\title{
Arm-twisting medical schools for core geriatric training
}

$\mathrm{T}$ he provision of geriatric training for undergraduate medical students should be a condition of accreditation of medical schools, as well as a competency tested on licensing exams. That stance lies at the core of a campaign by the Canadian Geriatrics Society (CGS) and the National Initiative for the Care of the Elderly to bolster physician capability to provide proper care to Canada's aging population.

But the four-year-old effort appears to have yielded little in the way of change and academic administrators argue there's no urgent need for change.

Advocates aren't persuaded.

Integration of core competencies regarding the care of elderly persons in medical school curricula across the country is "spotty," says Dr. Jasneet Parmar, chair of the CGS Medical Education Committee and geriatric undergraduate medical student training director at the Glenrose Rehabilitation Hospital in Edmonton, Alberta. "We're still in the stage where we're trying to get our medical schools to recognize the need for graduating medical students to have some basic skill sets in the care of the frail and elderly."

The CGS committee began developing a set of core competencies in the care of older persons for Canadian medical schools in 2005. The list of 20 competencies was completed, and then approved by the CGS in 2008. A subsequent request for their national adoption was submitted to the Committee on the Accreditation of Canadian Medical Schools/Liaison Committee on Medical Education, and to the Medical Council of Canada for their inclusion in qualifying examinations. The competencies were also forwarded to the deans of all medical schools, asking that they modify their curricula to include appropriate instruction in the area.

The competencies include the ability to perform cognitive impairment assessments, the capacity to manage medications in conjunction with the pharmacokinetic changes that occur

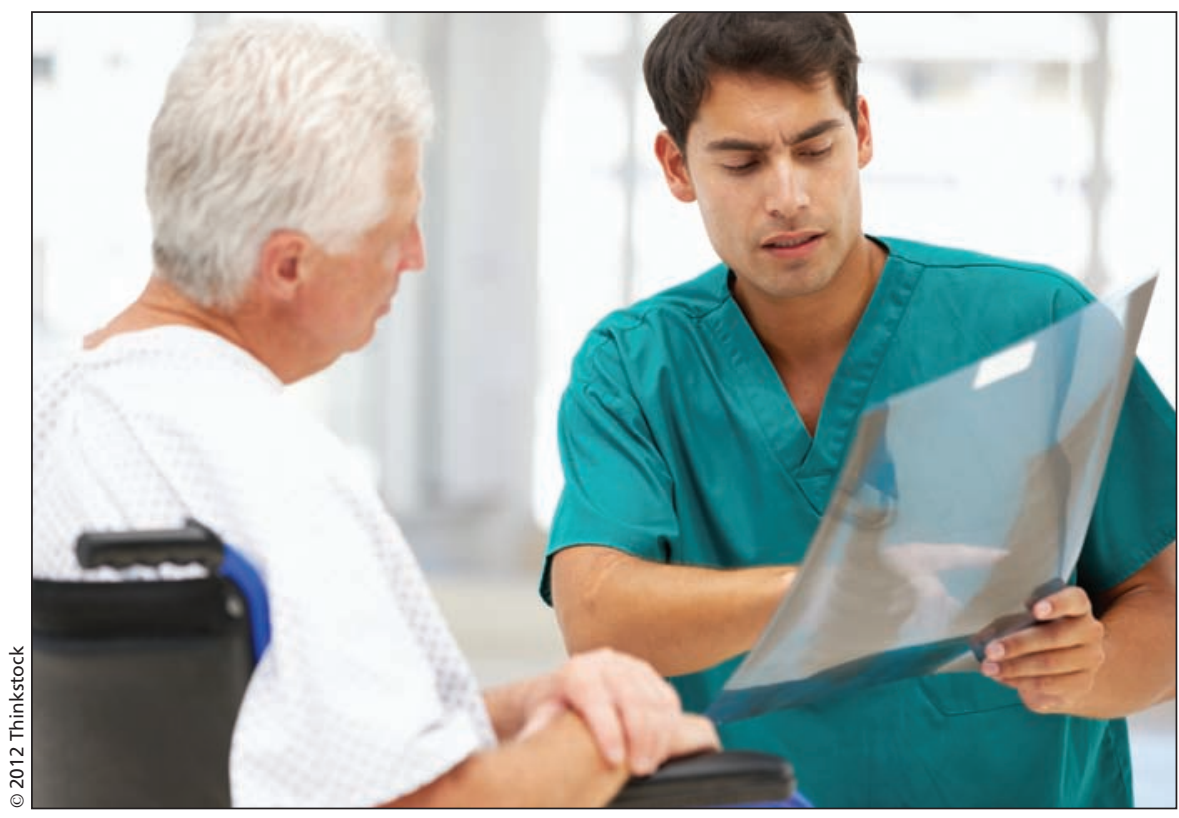

A survey of the geriatrics content included in undergraduate and postgraduate curricula indicated that very few institutions bolstered such instruction over a four-year period ending in 2009.

with aging and an understanding of the atypical presesentations of common medical conditions in an older person (http://canadiangeriatrics.ca /students/assets/File/Core_Geriatrics _Competencies_med_students.pdf).

A parallel process in the United States saw the Association of American Medical Colleges and the American Geriatrics Society develop a similar set of core geriatric competencies for medical students and those have been endorsed by the colleges, Jillian Lubarsky, senior communications coordinator for the American Geriatrics Society, writes in an email. But "these have not yet led to any specific changes in licensing exams or accreditation requirements."

Canadian medical administrators suggest additional instruction in geriatric competencies is unnecessary.

They are "very much part and parcel of what is in an MD curriculum currently," says Dr. Geneviève Moineau, secretary of the Committee on Accreditation of Canadian Medical Schools and vice president of education at the Association of Faculties of Medicine of
Canada. "These are obviously very important content areas and all of it would be currently part of any medical school curriculum."

Moreover, she argues, accreditation requirements should never be so precisely defined. "It's very important from an accreditation perspective that we not be too prescriptive because that's not how curriculum is really developed most of the time," Moineau says. "When the school develops its curriculum, it has to feel that it's relevant to its particular mission."

Moineau points to Canada's newest medical school - the Northern Ontario School of Medicine in Sudbury, Ontario, and Thunder Bay, Ontario as an example of the sort of flexibility that medical schools should be given with respect to curricula. Part of that school's mandate is the care of northern and Aboriginal populations, so "they've created a significant focus there. They have to be able to have that focus and yet respond to all of these standards within that focus."

Similarly, there does not appear to 
be any intention to bolster the testing of geriatric competencies in licensing exams.

The testing of such competencies is already covered off because content development test committees, whose members include physicians with expertise in geriatrics, have input into the final formulation of the exams, Jessica Hertzog, senior communications advisor for the council, writes in an email.

Some changes may occur, however, as a comprehensive review of the expectations for graduating medical students is currently being finalized by the council's objectives committee, Hertzog adds. As well, the council has launched "a blueprint project, which will ensure that the critical core competencies, knowledge, skills and behaviours required of a physician entering supervised and unsupervised practice are being appropriately assessed."

But lacking any manner of compulsion to provide more instruction in geriatric care, it appears that Canadian medical schools are disinclined to bolster such instruction of their own volition.

A survey of the geriatrics content included in undergraduate and postgraduate curricula indicated that very few institutions bolstered such instruction over a four-year period ending in 2009 (www.cgjonline.ca/index.php /cgj/article/download/11/35).

"The mandatory geriatrics content of the undergraduate curricula ranged between 10 and 299 hours, with a mean of 82," the survey stated. "Seven of 16 schools had a mandatory clerkship rotation of at least 1 week. Fourteen family medicine programs had a rotation in geriatric medicine and all psychiatry programs required a rotation in geriatric psychiatry. A geriatric rotation was mandatory for six internal medicine, six neurology, five physiatry, one orthopedic, and one emergency medicine program. In comparison to 2004-5, the mean hours of geriatrics teaching in the undergraduate curricula had increased from 78 to 82 . However, two schools saw a decrease in preclerkship teaching and one school lost a 2-week clerkship. Postgraduate requirements had changed little overall, with the exception that, for emergency medicine, geriatrics was now mandatory for only one program, instead of three."

"Although the total number of hours of teaching in geriatric medicine in the undergraduate curricula had increased slightly in 2008-09 compared to 2004-05, in some schools teaching hours were reduced," Dr. Janet Gordon, author of the study and geriatric undergraduate medical student teaching director at Dalhousie University in Halifax, Nova Scotia, concluded. "In the postgraduate curricula emergency medicine requirements for geriatrics were reduced. Of greater importance is determining which core competencies are being taught and mastered, and this is an area of ongoing study."

The failure of medical schools to bolster training in core geriatric competencies in recent years isn't surprising, says Dr. Christopher Frank, chair of the Health Care of the Elderly Program Committee at the College of Family
Physicians of Canada and past president of the Canadian Geriatrics Society. While the academic community is generally aware of the need to ensure that medical students and physicians have skills in geriatrics, "it's very inconsistently covered," Frank says. "Pretty much everybody I have spoken to would say that their medical schools are more aware of the problem, but really integrating geriatric education either in a block format or sort of throughout the curriculum is very variable, and in some places done superbly well and in other places with lots of work to do."

"I think everybody's got the message, but how far along the road people have come is, unfortunately, very variable still," Frank says, adding that the best case scenario for the core geriatric competencies may be their use "as a framework for any gains we can make in geriatric education."

Some medical students don't appear averse to the notion of increased geriatric training. "With the aging population that we have in Canada, it's important for everyone, all graduating medical students, to have a basic fundamental understanding of how to provide quality care for their patients. Part of the way that they can do so is by having a basic understanding of the core competencies," says Allison Mitchell, a student at University of Saskatchewan in Saskatoon and president of the National Geriatrics Interest Group. - Michael Monette, CMAJ and Andrea Hill, Ottawa, Ont.

CMAJ 2012. DOI:10.1503/cmaj.109-4195 